\title{
A COLETA DE DADOS EM ENFERMAGEM: RELATO DE UMA EXPERIENCIA DE ENSINO
}

\author{
Thelma Leile de Araijo* \\ Cibele Andrucioli de Mattos Pimenta* \\ Maria Julia Paes da Silva"* \\ Paolo Meneghin"* \\ Ana Cristina Mancussi e Faro*
}

ARAÚJO, T. L. de. et al. A coleta de dados em enfermagem: relato de uma experiencia de ensino. Rev. Enc. Ent. USP, v. 28, n. 1., p. 59-66, abril, 1994.

Avaliaçào de uma experiência de ensino de coleta de dados para enfermeiros, verificando de que forma este aprendizado tem modificado a prática de enfermagem. A populaçāo do estudo foi constituída por 84 enfermeiros de diferentes instituiçóes de saude e de ensino.

UNITERMOS: Coleta de dados. Educaçào em enfermagem.

\section{INTRODUÇĀO}

A Disciplina Fundamentos de Enfermagem I (DIFE) da Escola de Enfermagem da Universidade de São Paulo vem a longo tempo desenvolvendo trabalhos de pesquisa na sistematizaçāo da assistência de enfermagem, aplicando os resultados no ensino de graduação com a finalidade de contribuir para a melhoria da prática assistencial (PAULA et al, 1984; SANTOS et al, 1987; LAGANÁ et al, 1987, 1990).

Em pesquisa realizada por SILVA et al (1986), sobre o ensino da metodologia de assistência nas escolas de graduação em enfermagem da Grande São Paulo, as autoras constataram em entrevistas com docentes responsáveis por 70 disciplinas do tronco profissionalizante que $38(54,3 \%)$ adotavam o ensino da metodologia assistencial, enquanto $32(45,7 \%)$ não previam este ensino. Essas autoras ainda afirmaram que, embora o ensino da metodologia assistencial fosse desde a década de 70, esse assunto não era ministrado de maneira satisfatória, dicotomizando o saber e o fazer do enfermeiro. Muito provavelmente, em virtude dessa problemática, vários

Enfermejro. Aasistente do Departamento de Enfermagem Médico-Cirúrgico da Eecola de Enfermagem da USP.

*. Enfermeiro. Doutor do Deparcamento de Enfermegem Médico-Cirúrgica da Escola de Enfermagem da USP. 
enfermeiros expressaram sentir necessidade de que o processo de enfermagem fosse tratado com maior profundidade. Por este motivo a DIFE, em 1984, ministrou o primeiro curso sobre Processo de Enfermagem atendendo a estes profissionais.

A procura dos cursos extra-curriculares sobre processo de enfermagem, pelos enfermeiros, principalmente os de campo, superou as expectativas, pois as vagas eram preenchidas rapidamente, exigindo a repetição de outros cursos para atender a lista de espera.

Os cursos sobre processo de enfermagem ministrados pela DIFE englobavam aspectos tais como: teorias de enfermagem, com ênfase na teoria das necessidades humanas básicas; processo de enfermagem, genericamente e segundo Wanda Horta, histórico de enfermagem (entrevista e exame fisico), evolução e prescrição de enfermagem, sendo 10 horas para teoria, 10 horas para prática e 10 horas para discussão dos dados obtidos na prática do processo de enfermagem.

Neste conteúdo, a parte que enfocava a coleta de dados do paciente (entrevista e exame físico), era ministrada sucintamente abrangendo 4 horas do total do curso de processo de enfermagem. Como atividade a ser desenvolvida durante esses cursos, os alunos deveriam aplicar o processo de enfermagem na própria unidade de trabalho, sem supervisảo, com o intuito de obter dados para subsidiar posterior discussāo em grupo.

Por ocasiāo das discussōes os alunos, entre outras dificuldades encontradas, relatavam, com freqüência, ter problemas com a coleta de dados por falta de conhecimentos mais profundos sobre o assunto. A partir desta dificuldade, os coordenadores do curso de processo de enfermagem pensaram em oferecer cursos complementares de exame físico de enfermagem do adulto, sempre lembrando que além da abordagem do físico, a orientação para a coleta de dados por meio da entrevista faz parte dessa proposta.

A procura pelos cursos de exame fisico, porém, surpreendeu pelo grande interesse despertado em todos os profissionais e náo só nos que haviam freqüentado os cursos de processo de enfermagem.

Após o término do primeiro curso de exame físico, em fevereiro de 1990, os docentes de Fundamentos de Enfermagem I foram procurados para orientar e assessorar o desenvolvimento de cursos semelhantes em outras instituiçōes de ensino e assistenciais. Atendendo às solicitaçóes foram realizados 9 cursos sobre Exame Físico do Adulto, contendo em média 35 alunos por curso.

Desta forma, foi possível perceber a grande lacuna existente no conhecimento dos profissionais, em relação a este tema, tanto que hospitais de ensino solicitaram que fosse programada reciclagem sobre exame físico, destinada a todos os enfermeiros.

Os cursos oferecidos têm tido uma duraçāo média de 32 horas e abarcam conteúdo relativo à coleta de dados - entrevista e exame físico - enfocando o corpo humano por sistemas.

Atualmente, há interesse das instituiçōes de saúde que mantém programas de aprimoramento e residência em enfermagem que, tanto o curso de 
processo de enfermagem como o de exame fisico façam parte do conteúdo teórico-prático destinado aos residentes.

$\mathrm{Na}$ tentativa de relatar a experiência dos docentes da DIFE em ministrar cursos de exame físico e avaliar a repercussão desses cursos na prática profissional, foram estabelecidos os seguintes objetivos para este trabalho:

- identificar, por meio da opiniāo dos participantes dos cursos de exame físico, que contribuição o mesmo trouxe para sua prática profissional;

- verificar que alteraçoes foram introduzidas na sua prática de coleta de dados;

- investigar se os participantes dos cursos de exame fisico foram influenciados pelos mesmos, para a realização sistemática da coleta de dados;

- averiguar o interesse dos enfermeiros em aumentar os conhecimentos sobre coleta de dados e que estratégias sugerem para tal.

\section{MATERIAL E MÉTODO}

Os dados foram coletados através de questionário contendo 8 questōes abertas e fechadas (anexo). A populaçāo foi composta de 84 enfermeiros de diversos hospitais da capital e interior de São Paulo, que frequentaram os 3 últimos cursos sobre "Exame Físico do Adulto", desenvolvido por docentes da Escola de Enfermagem.

Os questionários foram entregues aas participantes imediatamente após o término do curso, em alguns casos, e em outros, houve um intervalo de até 3 meses para o seu preenchimento. O questionário não foi previamente testado. Visava levantar dados relativos à contribuição trazida pelo curso aos profissionais, a implementaçāo prática desta contribuiçāo e desejo de aumentar seus conhecimentos nesta área.

Procedeu-se à tabulação e análise dos dados, apresentados a seguir.

\section{DISCUSSĀO DOS RESULTADOS}

O estudo foi desenvolvido com os 84 questionários preenchidos por enfermeiros de diferentes hospitais. As respostas obtidas nas questōes abertas foram agrupadas por semelhança de expressóes e conceitos visando facilitar a apresentaçāo.

$\mathrm{Na}$ primeira questāo relacionada à contribuiçāo ou nāo do curso de exame fisico do adulto, 79 enfermeiros consideraram que o curso organizou informaçóes anteriores; 72 enfermeiros, que trouxe informaçōes novas, en- 
quanto 33 enfermeiros consideraram ter o curso modificado conceitos técnicos anteriores.

Apenas 3 enfermeiros consideraram que o curso nâo lhes trouxe informaçōes novas e outros 2, que nāo modificou conceitos anteriores.

Quatro enfermeiros citaram, ainda na referida questão, a necessidade de que o curso tivesse também como enfoque a abordagem do exame físico de crianças e de recém-nascido. $E$ interessante observar que o curso teve como única proposta o conhecimento físico do adulto, haja visto o seu nome.

Citadas apenas uma vez temos as seguintes afirmaçoes: o curso deu maior autonomia técnica; realçou a necessidade de prestar cuidados centrados nos pacientes e que o curso trouxe-lhe agilidade, segurança e diminuição da ansiedade.

Após o término do curso ou mesmo durante sua ocorrência, a maioria dos enfermeiros (57) procurou treinar ou aplicar alguma técnica proposta para o levantamento de dados, enquanto 25 enfermeiros não treinaram e um näo respondeu à questäo.

As técnicas treinadas pelos enfermeiros foram:

QUADRO I - Rolação das técnicas citadas polos enfermeiros como treinadas durante ou após o Curso de Exame Físico do Adulto.

Técnicas

Palpação $N^{2}$ de enfermeiros

Ausculta 16

Entrevista 15

Observação

Percussão

Exame de mamas

Avaliação da dor

Exame de pele

Exame de genitália feminina

Inspeção

Exame de genitália masculina

Palpação abdominal

Exame de cabeça e pescoço

Exame neurológico

Anotaçōes

Educação para a saúde

Exame físico como um todo

Genitália infantil

A terceira questāo foi relativa às alteraçōes ou não, introduzidas pelos enfermeiros na coleta de dados que fazia anteriormente, sendo que 53 enfermeiros informaram que o curso introduziu alteraçóes, enquanto 29 consideraram que isto nảo ocorreu e desses, dois enfermeiros destacaram nảo trabalhar utilizando exame físico. Um enfermeiro năo respondeu à pergunta. 
As alteraçōes citadas pelos 53 enfermeiros estão relacionadas a seguir.

QUADRO II - Alteraçöes citadas como introduzidas na coleta que faziam anteriormente
Alteraçōes
Melhoria da prática do exame físico
$N^{2}$ de enfermeiros
Utilizaçāo de técnicas propedêuticas 16
Sistematização, observação e registro
Maneira de abordar os pacientes
Na avaliação neurológica
Na avaliaçāo de cabeça e pescoço
2
Na avaliação do tórax e da respiração
1
$\mathrm{Na}$ avaliação de mamas
Capacitaçāo para elaborar instrumento
de exame físico
1
Segurança e agilidade na assistência

Com relação à pergunta passaram a desenvolver o exame físico nos pacientes sistematicamente? 49 enfermeiros responderam que sim, e um deles destacou, em especial, o exame de mamas. Cumpre esclarecer que a maior parte dos respondentes trabalhavam em instituiçōes que utilizam uma sistemática de assistência de enfermagem.

Responderam que "não passaram a desenvolver" o exame físico, 30 enfermeiros, dos quais dois justificaram nảo fazer o exame fisico por estarem em atividades administrativas. Quatro enfermeiros não responderam.

Durante ou após o término do curso, 37 enfermeiros leram algum texto específico sobre o assunto, enquanto 46 referiram näo terem tido oportunidade de estudar. Um enfermeiro nāo respondeu.

Foi perguntado, para aqueles que trabalhavam com uma sistemática de assistência de enfermagem, se o curso de exame físico do adulto havia contribuído para essa prática e 69 enfermeiros responderam afirmativamente. Dos 6 que responderam nảo, 3 justificaram trabalharem apenas com recém-nascidos. Causa estranheza não conseguirem extrapolar o conhecimento adquirido ou abordado no curso para este grupo específico, uma vez que mesmo considerando várias diferenças alguns aspectos do exame físico do adulto e do recém-nascido são coincidentes.

Cabe também ressaltar que grande parte dos enfermeiros fizeram o curso voltado para o atendimento do adulto como exigéncia de uma instituiçāo.

Um enfermeiro informou não trabalhar com uma sistemática de assistência (mesmo estando em instituiçảo que adotava esta filosofia de trabalho. Os outros dois enfermeiros não justificaram a resposta negativa, Questāo $n^{2} 6$ ).

As formas de contribuição citadas pelos 69 enfermeiros, na questão $n^{2}$ 6 foram: ampliação do conhecimento (26); melhoria da prática (14); reciclagem de conhecimento (11); melhoria na coleta de dados (8); aumento na especi- 
ficidade do exame físico (5) e que deu oportunidade para tornar seguros, 3 enfermeiros.

A pergunta relativa às facilidades adquiridas no desenvolvimento do exame físico e que eram atribuídas ao curso, obteve 40 respostas relacionadas a seguir.

QUADRO III - Facilidades para a coleta de dados adquirldos no desenvolvimento do Curso de Exame Fisico do Adulto.

Facilidades $n^{9}$ de enfermeiros

Reciclou conhecimentos

Adquiriram maior destreza para

avaliação de pacientes

Possibilitou conciliação da teoria e prática

Melhoria da assistència

Dois enfermeiros ressaltaram que o fato "das aulas serem bem ministradas" foi um fator facilitador.

Com relaçāo às dificuldades atribuidas ao curso foram citadas 32 opiniōes, sendo a duraçäo curta do curso, lembrada por 9 enfermeiros; o fato do curso não oferecer parte prática por 7 outros; de ser voltado apenas para o adulto (5 enfermeiros); que o curso foi cansativo (5 enfermeiros); que ofereceu pouco material apostilado, por 3 enfermeiras; e de que foi oferecido em horário considerado impróprio por 2 enfermeiros. Um enfermeiro informou que a dificuldade era relacionada a sua falta de segurança.

Chama a atenção o grande número de enfermeiros (78) que manifestaram interesse em aumentar seu conhecimento nessa área (questāo $n^{9} 8$ ), justificando terem necessidade de aprimorar-se (28 enfermeiros); melhorarem a assistência (19); para sistematizar condutas (9); a mpliarem os conhecimentos em pediatria e com recém-nascidos (6); verem situaçōes diferentes (4); por realização profissional (4); para treinar novos grupos de enfermeiros (1) e um enfermeiro afirmou querer ampliar seu conhecimento por ser esta a primeira vez que ouvia o assunto.

Dos 5 enfermeiros que não manifestaram interesse no aumento de conhecimentos na área, apenas dois justificaram a resposta: um por querer se aprimorar na área administrativa e outro por preferir estudar a fundamentação científica do exame físico, que considerou ser anatomia e fisiologia.

A questão não foi respondida por um enfermeiro.

Quanto às estratégias que serão utilizadas para que os enfermeiros possam aumentar seu conhecimento, foram citadas: leituras (58 enfermeiros); prática do exame físico (31); freqüentar cursos (30); discussão com grupos (10); aulas práticas com especialistas no assunto (6); pesquisas (4); fazer exame fisico em crianças e recém-nascidos (4); participar de eventos (1). Um enfermeiro afirmou nāo saber qual seria a sua estratégia. 
Com referência a estratégia-leitura alguns enfermeiros destacaram que iriam estudar bibliografia indicada pelos docentes e não deixa de ser interessante verificar que, apesar dos participantes dos cursos se queixarem da inexistência de uma parte prática como conteúdo do mesmo, continuam colocando como maior estratégia para o seu desenvolvimento, as leituras. No entanto, menos da metade dos participantes (37) refere ter tido a oportunidade de ler algo sobre exame físico até o momento da coleta de dados.

\section{CONCLUSÕES}

Dos 84 enfermeiros entrevistados, 79 consideraram que o Curso de Exame Físico do Adulto organizou suas informaçōes anteriores a respeito do assunto; 72 enfermeiros relataram ter recebido informaçōes novas e 33 afirmaram que o curso modificou conceitos técnicos anteriores. Parece que os enfermeiros possuíam informaçōes a respeito do tema, mas de forma fragmentada e dissociada. No entanto, grande número referiu ainda ter aprendido aspectos novos e ter modificado conceitos anteriores.

Relativo à influência do curso na realizaçảo sistemática do exame físico, dos 84 respondentes, 53 informaram ter introduzido novas práticas na realização do exame físico e 49 passaram a desenvolvê-lo sistematicamente. As alteraçōes introduzidas na realizaçāo do exame físico relacionaram-se, segundo relato dos enfermeiros, à melhoria da habilidade na realização do exame e utilização de técnicas propedêuticas. A maioria (57) informou ter treinado ou aplicado técnicas propedêuticas após ou durante o curso.

Parece ter ocorrido modificaçōes na realização do exame físico, mesmo com enfermeiros que trabalhavam em instituiçōes onde já existia sistematização da assistência de enfermagem visto que os 69 enfermeiros que relataram estas modificaçōes trabalham com processo de enfermagem.

Como principais dificuldades atribuídas ao curso apontaram: a curta duraçāo, falta de parte prática e não entrega de apostilas. prática.

Cabe ressaltar que, em um dos cursos, foi introduzida uma parte

$O$ interesse em aumentar seus conhecimentos em exame fisico foi expresso por 78 enfermeiros. Leituras, "praticar" as técnicas de exame físico e freqüentar outros cursos foram as principais estratégias apontadas pelos profissionais para atingirem esta meta.

Em sua grande maioria, os enfermeiros relataram uma experiência bastante positiva relacionada à participação no curso de exame físico do adulto. Referiram ter ampliado seus conhecimentos e estarem introduzindo estas informaçōes em sua atividade profissional diária. Os autores acreditam que a melhoria da assistência possa advir do aperfeiçoamento da coleta de dados, visto a sua importância para o processo de cuidar. 


\section{CONSIDERAÇŌES FINAIS}

A possibilidade de desenvolver cursos sobre exame físico do adulto para enfermeiros permitiu aos docentes refletirem, estudarem e aperfeiçoarem sua abordagem sobre o tema. Sentiu-se a necessidade de introduzir este conteúdo, de maneira adaptada, aos alunos de Fundamentos de Enfermagem I. Uma maior homogeneizaçāo da linguagem entre os docentes foi conseqüência desta experiência.

Todos os cursos foram avaliados pelos seus participantes ao final. Esta avaliação subsidiou o aperfeiçoamento do curso.

Em algumas experiências foi possivel adaptar o curso à realidade daquele grupo.

Os autores acreditam ser esta uma forma de contribuição para a integraçāo docente-assintencial.

A grande receptividade e boa apreciaçāo destes cursos validaram a lacuna de conhecimento sobre o tema e pertinência de se refletir sobre o assunto com a comunidade de enfermagem.

Acredita-se que a melhoria da assistência possa advir deste tipo de experiência, visto a importância da coleta de dados em todo o processo de assistir.

ARAÚJO, T. L. de et al. Data collection in nursing: a teaching care report. Rev. Esc. Enf. USP, v. 28, n.1,p. 59-66, Apr., 1994.

After courses of Assessment of Adults questionares were sent to 84 nurses in order to know if their practice of physical examination was modified by them. These nurses worked in differents hospitals and graduated schools. The majority of them related that they improved their knowledge about the matter and modified their practice. 